\title{
AS CARACTERÍSTICAS DA PÓS-MODERNIDADE COMO INFLUÊNCIA ESTÉTICA DA VIDEOARTE CONTEMPORÂNEA
}

\author{
Susy Elaine da Costa Freitas*
}

RESUMO: O presente artigo tem como objetivo principal traçar um paralelo entre os elementos mais marcantes da pós-modernidade, levando em consideração a complexidade na conceituação do termo, e as características mais proeminentes observadas na videoarte contemporânea. Para tal, faz-se necessário apresentar a conceituação e caracterização a ser adotada para a videoarte e para a pós-modernidade, além de contextualizar estes termos para poder compreender de que maneira eles se apresentam relacionados. Posteriormente, o presente artigo busca identificar as características mais presentes nas diferentes visões acerca da pós-modernidade, de acordo com autores como Perry Anderson, Zygmunt Bauman, Stuart Hall, dentre outros, em diferentes obras realizadas por videoartistas.

PALAVRAS-CHAVE: Pós-modernidade. Videoarte. Estética.

\section{Pós-modernidade: conceitos e características}

Pós-modernidade, modernidade líquida, modernidade em um estágio 'avançado'. Não importa qual termo seja utilizado, é notável que a contemporaneidade abarca uma série de transformações em setores tão diversos como o social, o econômico e $\mathrm{o}$ artístico, todas compreendidas em algum desses termos. Mas quais seriam essas transformações, e por que elas terminam por caracterizar uma época de maneira tão peculiar? Para tentar responder a essa questão, primeiramente é necessário compreender o que seria a pós-modernidade, além de destacar suas características mais comuns de acordo com as visões de diferentes teóricos, numa tentativa de abrangê-la de maneira o mais completa possível.

O conceito de pós-modernidade é vago, não apresentando uma definição geral para si dentre os diversos teóricos que se debruçam sobre ela. É justamente por isso que o termo se desdobra dentre tantos outros. A complexidade abarcada

\footnotetext{
Universidade Federal do Amazonas. Bolsista da Coordenação de Aperfeiçoamento de Pessoal de Nível Superior (Capes). Imeio: freitas.sec@gmail.com.
}

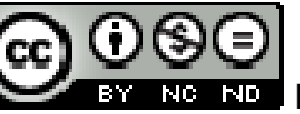

Texto Digital, Florianópolis, v. 8, n. 2, p. 68-82, jul./dez. 2012. ISSNe: 1807-9288 
pela pós-modernidade é exposta por Esperandio (2007) quando a autora afirma que

Não há como buscar uma verdade que se chama pósmodernidade. Mas há, sim, como colocar em evidência a construção de sentido sobre um processo de recomposição de diversos elementos (políticos econômicos, culturais, religiosos etc.), que leva à emergência do que se tem chamado hoje de pósmodernidade. (ESPERANDIO, 2007, p. 9, grifo da autora)

Apesar de toda a confusão que o termo pós-modernidade pode causar, algumas caracterizações de teóricos como Fredric Jameson e Michel Maffesoli dão conta de constatar algumas similaridades entre visões distintas. Exemplo disso é o fato de que ambos encaram a pós-modernidade como um fenômeno cultural. Featherstone afirma que em seus estudos Jameson "fala em pós-modernismo como uma lógica cultural, ou dominante cultural, que conduz à transformação da esfera cultural da sociedade contemporânea". (FEATHERSTONE, 1995, p. 26). Para Jameson (1993), a função do termo pós-modernidade seria

[...] correlacionar a emergência de novos aspectos formais da cultura com a emergência de um novo tipo de vida social e com uma nova ordem econômica - aquilo que muitas vezes se chama, eufemisticamente, de modernização, sociedade pós-industrial ou de consumo, sociedade da mídia ou dos espetáculos, capitalismo multinacional. (JAMESON, 1993, p. 27)

Maffesoli (1999), citado por Esperandio (2007), apresenta uma visão parecida quando afirma que "associar pós-modernidade e neoliberalismo é uma bobagem, pois o fundamento da pós-modernidade não é econômico" (ESPERANDIO, 2007, p. 6), destacando o imaginário social como um fato mais marcante para a construção de uma identidade 'pós-moderna'. Segundo Sanfelice (2003, p. 4), o filósofo Jean-François Lyotard também reconheceu na pós-modernidade uma mudança geral na condição humana, abrangendo os mais diversos setores da vida sem se restringir a apenas alguns deles. 
Coelho vai ainda mais fundo no caráter generalista que o conceito de pósmodernidade recebeu no decorrer de sua trajetória. $\mathrm{O}$ autor destaca novamente a complexidade do processo de transformação cultural que o termo carrega em si ao explicar que:

\begin{abstract}
Neste final de século que, já um pouco mais facilmente, é possível rotular de pós-moderno, tanto a tradicional concepção antropológica de cultura quanto categorias mais recentes como cultura superior, média (midcult), e de massa (masscult) discutidas no começo dos anos 60 por Dwight MacDonald, na esteira dos escritos da escola de Frankfurt, e em seguida vastamente popularizadas por Umberto Eco, entre outros -, sem esquecer conceitos similares do tipo cultura popular, cultura hegemônica, cultura dominada, cultura nacional-popular, não mais dão mais conta, sozinhos, da complexidade e diversidade da dinâmica cultural. (COELHO, 2005, p. 172, grifos do autor)
\end{abstract}

Para Anderson, a chave para a compreensão do que é a pós-modernidade é a instantaneidade. De acordo com o autor, o termo pós-moderno "é sempre em princípio o que se deve chamar um presente absoluto. [...] Ele cria uma dificuldade peculiar para a definição de qualquer período posterior, que o converteria num passado relativo" (ANDERSON, 1999, p. 20). É dessa maneira que se pode destacar como uma das características mais proeminentes da pósmodernidade a relação peculiar que este tem com o tempo, que pela primeira vez se desprende das amarras do espaço para se tornar uma unidade independente.

Pontes (2003, p. 50) afirma que essa característica de relativização do tempo está presente tanto nas obras de Maffesoli, que a chama de 'presenteísmo', quanto de Jameson, que utiliza o termo 'presente perpétuo'. Bauman também destaca o caráter relativo e cada vez mais subjetivo do tempo na pós-modernidade, a qual ele chama de 'modernidade líquida'. De acordo com o autor, já no começo da era moderna se observava uma emancipação do tempo em relação ao espaço, na qual "a relação entre tempo e espaço deveria ser de agora em diante processual, mutável e dinâmica, não predeterminada e estagnada" (BAUMAN, 2001, p. 131).

É dessa maneira que a instantaneidade se sobrepõe como valor positivo em lugar do fixo e durável, ou, como o próprio Bauman coloca, há uma "despreocupação 
com a eterna duração em favor do carpe diem" (BAUMAN, 2001, p. 144, grifo do autor). O que resulta dessa nova maneira de se relacionar com o tempo é a quebra da sensação de limites:

A instantaneidade (anulação da resistência do espaço e liquefação na materialidade dos objetos) faz com que cada momento pareça ter capacidade infinita; e a capacidade infinita significa que não há limites ao que se pode ser extraído de qualquer momento - por mais breve e "fugaz" que seja. (BAUMAN, 2001, p.145)

A desconstrução das barreiras entre o pessoal e o público também pode ser encarada como uma característica própria da pós-modernidade. Em relação a isso, Esperandio mais uma vez recorre a Maffesoli quando afirma que o particular é cada vez mais exposto e, fazendo com que as emoções compartilhadas culminem no nascimento das tribos pós-modernas. De acordo com a autora, tal tendência "tem a ver com o desejo, com processos identificatórios que favorecem a construção de 'comunidades' ('tribos') cuja vitalidade permanece enquanto duram o desejo e a sensação de identificação" (ESPERANDIO, 2007, p. 62).

Bauman também destaca que a quebra dos limites entre o privado e o público pode ser encarada de maneiras diversas na pós-modernidade. Enquanto que pensadores como Habermas entendem tal fenômeno como uma 'invasão' do privado pelo público, Bauman rebate tal ponto de vista ao afirmar que:

O que parece estar em jogo é uma redefinição da esfera pública como um palco em que dramas privados são encenados, publicamente expostos e publicamente assistidos. A definição decorrente de "interesse público", promovida pela mídia e amplamente aceita por quase todos os setores da sociedade, é o dever de encenar tais dramas em público e o direito do público de assistir à encenação. (BAUMAN, 2001, p. 83)

O que ocorre nesse processo de transformação do subjetivo na pós-modernidade não é apenas uma maior exposição do que outrora era privado. Para Hall (2005, p. 12), o sujeito pós-moderno possui uma identidade fragmentada e não permanente, refletindo-se aí na quebra de barreiras outras além das de público e 
privado. O autor também frisa que esse sujeito não é mais definido biologicamente como em épocas anteriores, mas sim historicamente. De acordo com Hall (2005),

[a] identidade torna-se uma "celebração móvel": formada transformada continuamente em relação às formas pelas quais somos representados ou interpelados nos sistemas culturais que nos rodeiam (HALL, 1987). E definida historicamente, e não biologicamente. $O$ sujeito assume identidades diferentes em diferentes momentos, identidades que não são unificadas ao redor de um "eu" coerente. (HALL, 2005, p. 12-13)

A fragmentação não se limita à construção do sujeito pós-moderno. Ela também pode ser observada no encontro não necessariamente conflituoso entre diferentes pontos de vista, filosofias e outros saberes na contemporaneidade. Mais uma vez, a complexidade do exame da contemporaneidade a partir dos olhos de uma pósmodernidade é uma influente para tal fragmentação. Segundo Connor, "estamos no e pertencemos ao momento que tentamos analisar, estamos nas e pertencemos às estruturas que empregamos para analisá-lo" (CONNOR, 1993, p. 13).

Ora, após toda uma trajetória de elaboração de diversos paradigmas do conhecimento humano, inevitavelmente chegaria o ponto em que o acúmulo do que Lyotard chama de metanarrativas geraria opções diversas de se encarar a realidade. Esperandio explica melhor essa questão ao afirmar que para Lyotard, "a condição pós-moderna define-se como a perda da credibilidade nas metanarrativas (freudismo, marxismo, funcionalismo), mas isso não significa seu desaparecimento. Elas apenas se tornam 'menores' e competitivas entre si" (ESPERANDIO, 2007, p. 43). É essa competitividade que leva Eagleton (1998, p. 127-128) a constatar as contradições da pós-modernidade, encarando-a tanto libertária quanto autoritária, tanto hedonista como repressora, tanto múltipla como monolítica.

Quebra das fronteiras entre tempo e espaço, entre público e privado e de paradigmas. Partindo dessas características primordiais, o presente artigo busca 
as relações entre a pós-modernidade e a estética da videoarte contemporânea. Para tal, faz-se necessário uma explanação acerca dessa forma peculiar de manifestação artística.

\section{Arte em vídeo e estética da videoarte}

Se para Arlindo Machado (2002, p. 20) a arte sempre foi produzida com os meios de seu tempo, a utilização do vídeo para o desenvolvimento de formas de expressão artística na contemporaneidade é um passo natural. Esse passo implica uma fuga das concepções clássicas da arte e aponta uma direção que leva à agregação de diferentes meios para formar uma obra. Santaella (2008, p. 36) também apresenta uma opinião semelhante quando afirma que o artista tem como desafio reinaugurar as linguagens da arte ao utilizar os meios de seu tempo. Na contemporaneidade, os meios mais proeminentes são as tecnologias digitais, tal como o vídeo.

O vídeo é um meio de identidade múltipla. Ele carrega características do cinema, pela fotografia e pela música, por exemplo, integrando sua própria natureza a eles. Mello (2008, p. 26) afirma que o vídeo, além de múltiplo, é também fundamentalmente instável e mutante. Machado apresenta uma visão semelhante quando constata que "a imagem eletrônica é muito mais maleável, plástica, aberta à manipulação do artista, resultando, portanto, mais suscetível às transformações e anamorfoses" (MACHADO, 2007, p. 25-26). Reis Filho (2007, p. 3) também chega a mesma conclusão ao encarar o vídeo como uma linguagem híbrida, descontínua e mutante.

Segundo Lima, o início da videoarte remonta à década de 1960, período marcado por experimentações e contraposições com as práticas artísticas mais clássicas. O coreano Nam June Paik é conhecido como um dos pioneiros da videoarte, pois nessa época ele "começa a explorar as possibilidades da imagem eletrônica na busca de uma imagem que fosse alternativa àquela usada na televisão" (LIMA, 2010, p. 2). Para Dempsey (2003, p. 257), suas obras apropriaram-se da sintaxe 
da linguagem televisiva, aproveitando a espontaneidade, descontinuidade e potencial de diversão do meio, demarcando assim a primeira das várias hibridizações do vídeo.

Muitas das obras de Nam June Paik não utilizaram câmeras para a captação de imagens, mas ainda assim as intervenções guiaram o trabalho do artista e de muitos realizadores que o sucederam. Zanini (2007, p. 51) também destaca como artista precursor da videoarte o alemão Wolf Vostell e sua produção de décoll/age. Apesar do trabalho desses dois artistas remontarem ao início da década de 1960, e apesar de serem muitos os artistas que utilizaram o vídeo desde então, Zanini (2007) afirma que:

\begin{abstract}
A breve história da videoarte - uma denominação geralmente aceita - tomou densidade nestes últimos seis ou sete anos, encontrando um terreno muito favorável nos Estados Unidos e Canadá, enquanto na Europa não raros extratos culturais procuraram resistir à "invasão" eletrônica. (ZANINI, 2007, p. 52)
\end{abstract}

Como se pode notar já através dos trabalhos dos precursores Paik e Vostell, as experimentações da videoarte e suas relações com os outros meios vão além do produto televisivo. Prova disso são as videoinstalações, que propiciam o "deslocamento do espectador de seu caráter passivo para ativo, assim como a inserção de multinarrativas e de pontos de vista distintos" (LIMA, 2010, p. 3). Lima (2010, p. 4) igualmente destaca a relação direta entre a música e o vídeo através do sintetizador, que converte imagens em ondas sonoras.

Antes de falar de uma estética da videoarte, é preciso explicar o que é a estética em si. Arantes explica que, para Platão, o belo estético é subordinado à moral e a intelectualidade, sendo uma manifestação de algo que vai muito além da forma física a ser apreciada. A autora afirma que "a estética tradicional [...] é uma estética da transcendência: cópia de um mundo pré-fixado, dado, imutável e fixo" (ARANTES, 2008, p. 23). No Renascimento, a estética se modifica, prezando mais pela imitação do real (mimese), pela perspectiva e pela construção de "dispositivos tecnocientíficos destinados a dar 'objetividade' e 'coerência' ao 
trabalho de produção da imagem pictórica" (ARANTES, 2008, p. 23-24). Como campo filosófico, a estética remonta ao século XVIII com Alexandre Gottlieb Baumgarten, a partir do qual "se sobrepõe expressamente a outras possibilidades do pensamento, enquanto um tema autônomo" (KIRCHOF, 2003, p. 27). Arantes (2008) sumariza a trajetória da estética até modernidade ao afirmar que

No campo das práticas artísticas e midiáticas, poderíamos dizer que, assim como o Renascimento foi marcado pela perspectiva, pelas técnicas de visualização - reveladores dos pressupostos racionalistas e cartesianos da época -, os séculos XIX e XX parecem ter sido pautados pelas pesquisas na criação do movimento, pelo desenvolvimento de máquinas que simulam o movimento, pelo desenvolvimento de tecnologias cinemáticas, isto é, pela incorporação da dimensão do tempo no campo mais geral da arte. (ARANTES, 2008, p. 26)

É difícil definir a estética da videoarte, cuja maior característica é a hibridização com outros meios. Porém, alguns caracteres se destacam no decorrer da história da videoarte e dão um direcionamento esse campo. Primeiro, é preciso compreender a natureza da imagem eletrônica. No vídeo analógico, a imagem é formada por centenas de linhas luminosas; no vídeo digital, milhares de pontos de cor (chamados pixels) cumprem essa tarefa. Logo, o que compõe a imagem completa são a intensidade, os valores cromáticos e a duração dos pontos na tela. É dessa maneira que "a imagem completa - o quadro videográfico - não existe mais no espaço, mas na duração de uma varredura completa da tela, portanto no tempo". (MACHADO, 2007, p. 24). Arantes (2008) complementa a ideia de relevância do tempo e de seu fluir para compreender a estética do vídeo ao afirmar que

É com esse espírito de obsessão pela ideia do movimento que surgem as experimentações em vídeo dos anos 60 . Será na direção das distorções, da desintegração das formas e da ruptura com aquilo que é fixo e, também, na direção da incorporação da dimensão do tempo e do movimento que a videoarte encontra sua força estética fundamental. (ARANTES, 2008, p. 28)

De fato, na contemporaneidade se observa que o movimento passou a integrar o hall de características estéticas envolvidas com a evolução dos meios 
tecnológicos e, por conseguinte, da arte desenvolvida a partir deles. Arantes afirma que "uma das grandes novidades colocadas pelas tecnologias contemporâneas não é simplesmente o movimento, mas, antes, o interfaceamento, os processos relacionais que se estabelecem da construção da obra/mundo" (ARANTES, 2008, p. 29). A autora também frisa que, independente de quais teorias sejam utilizadas como ponto de partida do estudo da estética da arte contemporânea, uma variável sempre se repete:

[...] o debate acerca dos novos formatos perceptivos e cognitivos trazidos pelas tecnologias contemporâneas, formatos que colocam em cena a ideia do tempo real, das trocas de informação, dos interfaceamentos humano-maquínicos, dos fluxos de informação e da visão sistêmica demanda pelas tecnologias contemporâneas. (ARANTES, 2008, p. 29)

Lima (2010, p. 3) aponta outros elementos que perpassam a estética do vídeo. A autora destaca no trabalho do teórico Phillipe Dubois sobre a mixagem de imagens videográficas, no qual ele destaca a sobreimpressão (sobreposição de imagens translúcidas), os jogos de janelas (recortes geométricos e fragmentos em um mesmo quadro) e a incrustação (utilização do chroma key, ou seja, de um buraco na imagem preenchido por parte de outra imagem); ou seja, a fragmentação e complexidade da imagem.

A complexidade também surge na visão de Arantes, para quem "as novas tecnologias midiáticas [incluindo-se aí o vídeo] instauram uma estética de fluxo, daquilo que se dá em trânsito e em contínuo devir" (ARANTES, 2008, p. 21, grifo da autora). A autora explica melhor o conceito de fluxo no contexto das artes contemporâneas:

O conceito de fluxo, como metáfora para pensar a estética contemporânea surge, portanto, como contraponto aos discursos estéticos da tradição, que pregam a forma fixa e perene: índices de beleza, da objetividade e do princípio de verossimilhança. (ARANTES, 2008, p. 22) 
A obra em fluxo, não mais acabada, mas em processo, apresenta também em sua estética outro caractere marcante: a câmera que se volta para o artista. Acompanhando a evolução da videoarte brasileira é possível perceber as diferentes maneiras com que esse olhar sobre si atua. Machado (2007, p. 17) explica que a fase inicial da história da videoarte brasileira, na qual os artistas buscaram no vídeo um suporte para romper com os esquemas estéticos e mercadológicos da pintura de cavalete, foi marcada pelo "registro do gesto performático do artista. Dessa forma, consolida-se o dispositivo mais básico do vídeo: o confronto da câmera com o corpo do artista" (MACHADO, 2007, p. 21).

O confronto citado por Machado não tinha apenas fins de registro, mas também de subjetividade, conforme se pode comprovar com a videoarte 'Marca Registrada' (1975), de Letícia Parente. Na obra, Parente borda na planta do próprio pé os dizeres "made in Brasil", registrando o ato num big close up. $\mathrm{O}$ videoartista Rafael França também exemplifica a presença do artista na obra, pois em seus vídeos os "os personagens quase sempre se apresentam falando diretamente à câmera, como se estivessem fazendo uma confissão ao espectador" (MACHADO, 2007, p. 23). Trabalhos como 'Prelúdio de uma morte anunciada' (1991), videoarte de França que Machado (2007, p. 23) afirma ser quase o registro da morte pela sua própria vítima (no caso, o artista, que veio a falecer pouco tempo depois por complicações geradas pelo vírus da AIDS), é igualmente impactante enquanto exemplo de obra que permeia profundamente questões subjetivas.

\section{Uma videoarte pós-moderna}

Como características proeminentes da estética da videoarte destacaram-se no presente trabalho a hibridização do vídeo com outros meios, a fragmentação, a agilidade do tempo da imagem, a construção da obra como processo e o potencial de intensa subjetividade. Percebe-se de início que esses elementos guardam certa similaridade com aqueles aqui expostos como pertencentes à caracterização da pós-modernidade, a saber: quebra das fronteiras entre tempo e 
espaço e entre público e privado e a complexidade gerada pela profusão de saberes em interação sem um paradigma regulador. Mas de que maneira se dá o encontro entre a pós-modernidade e a videoarte através de sua estética?

Se na pós-modernidade a quebra das fronteiras entre tempo e espaço acontecem em grande parte graças aos recursos tecnológicos, que permitem a conexão virtual entre pessoas e máquinas fisicamente distantes, na videoarte essas fronteiras também se tornam fluidas graças aos meios. Seja pela manipulação, hoje corriqueira, do tempo das imagens registradas através do slow motion ou fast forward, seja em projetos envolvendo videoperformance, por exemplo, percebe-se que a independência do tempo em relação ao espaço se dá em diversos formatos de videoarte. Além disso, o tempo, visto na contemporaneidade pós-moderna como continuum, influencia diretamente na condição da obra como processo, e não mais como resultado final e acabado deste.

A instantaneidade temporal típica da pós-modernidade também influencia, juntamente com a possibilidade gerada pela tecnologia, a proliferação de um ramo da videoarte cuja estética exemplifica claramente a correlação entre pósmodernidade e arte em vídeo nesse quesito: a videoperformance online. Se a videoperformance já é marcada pelo improviso e pela criação da obra de maneira espontânea, no ambiente online, capturada por webcams ou transmitida em tempo real a partir de câmeras digitais, a imagem chega ao extremo. Por um lado, a obra é "degustada" instantaneamente; por outro, uma eventual captura da imagem por algum dos internautas pode vir a se tornar outro produto através de remixagens e releituras, gerando uma nova obra e ressignificando o processo inicial que constituía a videoperformance online.

Constata-se também a partir da aproximação entre a profusão de diferentes saberes típica da pós-modernidade se relaciona principalmente com a fragmentação das imagens na videoarte. Incontáveis trabalhos nesse campo se caracterizam pelo alto número de cortes, pelo encontro de imagens diversas na sobreimpressão, jogos de janelas e incrustações citadas por Lima (2010, p. 3), 
dentre tantos outros recursos. Mais que apresentar quantitativamente um grande número de imagens dispostas num período de tempo determinado pela edição, essa característica dá à obra uma complexidade qualitativa, pois tem o potencial de abarcar muitas informações através dessas imagens.

A falta de um paradigma regulador na pós-modernidade influencia igualmente a hibridização no que diz respeito aos meios utilizados para construir a obra. Tendo a videoarte uma propensão a agregar características de meios diversos como a televisão, o cinema, a fotografia ou a pintura, ela não se guia unicamente por uma hipotética estética única do vídeo, fugindo constantemente de regras que poderiam inibir construções originais. A ausência de limites na absorção da influência de outros meios deixa a cargo do artista tentar pré-determinar, dentre tantas opções, quais serão essas influências. Essa é uma das maneiras que a complexidade da pós-modernidade se expressa esteticamente na videoarte.

Como último paralelo entre a pós-modernidade e a estética da videoarte proposto no presente trabalho coloca-se a quebra dos limites entre público e privado e a questão da subjetividade. Esta é expressa na videoarte em especial pelo papel de destaque que o corpo humano tem desempenhado em muitas obras significativas. A videoarte de Suzie Silver "A Spy (Hester Reeve Does The Doors)" (1992), analisada por Furtado (2009), exemplifica isso por trabalhar diretamente com o corpóreo enquanto possibilidade de comunicar uma mensagem que, nesse caso, relaciona-se à sexualidade.

Vale destacar que não é apenas com essa finalidade que o corpo ou outros aspectos da vida íntima se expõem na videoarte. A videoinstalação 'Passarela', de Danillo Barata, por exemplo, foi analisada por Couto (2009) como sendo uma crítica à imposição dos padrões de beleza contemporâneos, sem utilizar diretamente caracteres ligados à sexualidade. Já na videoarte ' $\mathrm{Na}$ tormenta' (2011), de Fabiano Barros, o artista volta a câmera para sua própria performance. Nessas diversas manifestações artísticas se observa que a condição humana, o corpo e as questões subjetivas apresentam um 'eu' cujo grau de exposição se 
expande de acordo com o desejo do artista, e não por uma delimitação imposta por um modelo artístico.

\section{Considerações finais}

A videoarte trabalha não apenas com os meios de seu tempo, mas apresenta temas e objetos típicos da contemporaneidade que determinam diretamente a estética dessa forma de arte. Sendo a contemporaneidade o terreno em que se desenrola o pós-moderno, a estética da videoarte e as características da pósmodernidade apresentam uma ligação direta, com estas últimas influenciando a construção das imagens e as formas de sentir a videoarte.

A exposição do íntimo, a independência do espaço em relação ao tempo e a utilização das mais diferentes técnicas, pontos de vista e recursos na obra de arte em vídeo evidenciam que a pós-modernidade se faz presente nessa manifestação artística desde a sua concepção até o seu resultado. Aliás, a própria condição da obra como processo, comum não apenas à videoarte como também à arte contemporânea em geral, evidencia isso ao possibilitar uma maior complexidade à videoarte, que conta cada vez mais com a interação, a manipulação do público e a espontaneidade da performance para sua construção.

Constata-se, portanto, que a estética da videoarte é um reflexo de seu tempo. Esta imprime um novo modo de sentir a obra que, ao contrário das obras de arte clássicas, pressupõe cada vez mais o entendimento de que o produto da expressão artística único para cada indivíduo e que não deve obrigatoriamente ser apenas admirado de seu pedestal, mas manipulado, discutido, reconstruído. Reconhece-se então no paralelo entre a videoarte e a pós-modernidade a complexidade não apenas de uma forma de expressão artística, mas da própria condição humana. 


\section{THE CHARACTERISTICS OF POSTMODERNITY AS AN INFLUENCE IN CONTEMPORARY VIDEO ART AESTHETICS}

ABSTRACT: This article aims mainly to draw a relation between the most striking elements of postmodernity, taking into account the complexity in the conceptualization of the term, and the main characteristics seen in contemporary video art. For such purpose, it is necessary to present the conceptualization and characterization to be adopted for video art and postmodernity, and contextualizing these terms in order to understand how they are related to each other. Subsequently, this article aims to identify the characteristics present in different views about postmodernity, according to authors such as Perry Anderson, Zygmunt Bauman, Stuart Hall, among others, in different works by video artists.

KEYWORDS: Post-modernity. Video art. Esthetics.

\section{Referências}

ANDERSON, Perry. As origens da pós-modernidade. Rio de Janeiro: Jorge Zahar, 1999.

BAUMAN, Zygmunt. Modernidade líquida. Rio de Janeiro: Zahar, 2001.

COELHO, Teixeira. Moderno pós-moderno: modos e versões. São Paulo: lluminuras, 2005.

CONNOR, Steven. Cultura pós-moderna: introdução às teorias do contemporâneo. São Paulo: Loyola, 1993.

COUTO, E. Danillo Barata: as fronteiras tecnológicas do corpo-imagem. In: Cultura Visual. n. 12. Salvador: EDUFBA, 2009. p. 77-85.

DEMPSEY, Amy. Estilos, escolas e movimentos: guia enciclopédico da arte moderna. São Paulo: Cosac \& Naify, 2003.

EAGLETON, Terry. As ilusões do pós-modernismo. Rio de Janeiro: Jorge Zahar, 1998.

ESPERANDIO, Mary Rute Gomes. Para entender pós-modernidade. São Leopoldo: Sinodal, 2007.

FEATHERSTONE, Mike. Cultura de consumo e pós-modernismo. São Paulo: Studio Nobel, 1995.

FURTADO, Teresa. Personae Masculinas na videoarte de mulheres. In: Ex aequo. n. 20, ISSN 0874-5560. 2009. p. 65-79.

HALL, Stuart. A identidade cultural na pós-modernidade. Rio de Janeiro: DP\&A, 2005. 
KAPLAN, Ann E. O mal-estar no pós-modernismo: teorias, práticas. Rio de Janeiro: Jorge Zahar, 1993.

PONTES, Pedro. Linguagem dos videoclipes e as questões do indivíduo na pósmodernidade. In: Sessões do imaginário, n. 10. 2003. p. 47-51.

SANFELICE, José Luis. Pós-modernidade, globalização e educação. In: LOMBARDI, José C. (org.). Globalização, pós-modernidade e educação: história, filosofia e temas transversais. São Paulo: Autores associados, 2003.

Texto recebido em 30/09/2012. 